\title{
De las granjas del Jura al valle de M'Zab. Influencias de lo vernáculo en Le Corbusier
}

\author{
From the farms of the Jura to the valley of M'Zab. \\ Influences of the vernacular in Le Corbusier
}

\section{Resumen} del valle del M’Zab, previos a la presentación del Plan Obús para Argel. Su especial predilección por residir en antiguas granjas de La Chaux-de-Fonds o las anotaciones en sus cuadernos de viajes acerca del cubismo que reconocía en las humildes viviendas del sur de España son instantáneas de una experiencia mucho más profunda del arquitecto suizo con lo vernáculo. Lo vernáculo muestra

María Mestre-Martí* maria.mestre@upct.es continuidad en su evolución personal desde una etapa temprana de aprendizaje hasta la formación de un lenguaje arquitectónico propio, pudiendo identificar cuatro etapas con diferencias de matiz (regionalismo, apertura a nuevos lenguajes, purismo, brutalismo). El objetivo de la investigación es determinar el papel que desempeñó lo vernáculo en su pensamiento y obra desde la década de 1910 hasta sus proyectos de 1930.

Palabras clave: Le Corbusier; arquitectura vernácula; arquitectura moderna; vanguardia; tradición.

\section{Abstract:}

Le Corbusier's attraction to vernacular architecture can be seen in his early drawings of the rural landscape of the Jura, when he was still a child, as well as in his drawings of the houses in the M'Zab valley prior to the presentation of the Plan Obus for Algiers. His special predilection for residing in old farmhouses in La Chaux-de-Fonds or the notes in his travel notebooks about the Cubism he recognised in the humble dwellings of southern Spain are snapshots of the Swiss architect's much deeper experience of the vernacular. The aim of the research is to determine the role played by the vernacular in Le Corbusier's thought and work from the 1910 s to the 1930 s projects. The research establishes the vernacular as a determining aspect in his training and attributes to it the shaping of an own architectural language from the 1910s to the projects of the 1930s. The vernacular shows continuity in his personal evolution, identifying four stages with differences of nuance (regionalism, openness to new languages, purism, brutalism).

Keywords: Le Corbusier; vernacular architecture; modern architecture; avantgarde; tradition. 


\section{Introducción}

En 1943 Le Corbusier escribía en Entretien avec les étudiants des écoles d'architecture (1957) en torno a tres términos, "invención arquitectónica", "tradiciones populares" e "historia", que muestran de forma significativa su actitud frente al proyecto de arquitectura a lo largo de su trayectoria. Ese pasado al que Le Corbusier se refería daba cabida, por un lado, a una larga tradición arquitectónica, clásica, de estilos. Por otro, a la arquitectura vernácula de distintas regiones, cuyo interés demostró a lo largo de su carrera, y que nos ha llegado a través de numerosos escritos, dibujos e incluso por las sugerencias contenidas en su obra construida.

Nos referimos al concepto de lo "vernáculo" como adjetivo para describir a un tipo concreto de arquitectura que tiene que ver con lo "nativo". En nuestra investigación, emplearemos la expresión "vernáculo" porque es aplicable a una amplia variedad de situaciones, debido a la propia connotación del término, menos específico y restrictivo que otros como "popular", "anónimo", "rural" o "primitivo"1. El propio Le Corbusier empleó distintos términos, como por ejemplo "primitivo" al referirse al hombre primitivo, sus medios primitivos y templo primitivo en Vers une architecture o Une maison-un palais; "salvaje" para referirse al arte y la casa del campesino en Le voyage d'Orient, y otras expresiones como la "casa del campesino", "cabaña del pescador", que hacen referencia al concepto de "vernáculo" en Une maison-un palais.

La relación de Le Corbusier con este tipo de arquitectura ha sido, y sigue siendo, objeto de estudio por parte de investigadores, como consecuencia de una actitud revisionista del Movimiento Moderno en las últimas décadas. Autores como Brooks (1997), Benton (1987), Baker (1996) o Daza (2015) han centrado sus investigaciones en periodos o aspectos significativos de su vida y obra. Sin pretender ser investigaciones específicas sobre cuestiones vernáculas, sí que aportan datos que convierten este aspecto en un denominador común que pone de manifiesto la importancia de esta arquitectura en su vida y obra. Otros autores como Lejeune y Sabatino (2010), o Vogt (1998) si han centrado sus investigaciones en cuestiones específicas sobre arquitectura vernácula.

En esta línea de trabajo se sitúa esta investigación, en la que se pretende rastrear la huella de lo

\footnotetext{
No existe un criterio único para denominar a este tipo de arquitectura. Según la R.A.E. el término "vernáculo" significa "dicho especialmente del idioma o la lengua: doméstico, nativo, de nuestra casa o país". Observamos que las referencias son tan solo de tipo lingüístico. Es el significado "nativo" de la palabra latina vernaculus el que otorga sentido a la expresión "arquitectura vernácula" como clara expresión metafórica entre la lengua y la arquitectura.
}

vernáculo en la obra y pensamiento de Le Corbusier durante un periodo y un contexto que definimos en el siguiente apartado.

\section{Materiales y métodos}

La dificultad que entraña examinar influencias con objetividad, cuyo análisis, salvo casos fidedignos, está sujeto a una interpretación subjetiva, ha determinado la construcción de esta investigación, estableciendo previamente unas directrices a seguir:

\subsection{Planteamiento de preguntas}

A grandes rasgos, se pueden resumir en tres los puntos fundamentales en los que se centra la investigación de este trabajo:

Formación: ¿Qué papel desempeñó la componente vernácula en su formación durante su época de juventud?, ¿cuáles fueron los personajes de la cultura y la arquitectura de la época que, con sus teorías y visión sobre lo vernáculo, influenciaron a Le Corbusier durante los años clave en su formación?, ¿qué enseñanzas le transmitieron?

Viajes realizados: Teniendo en cuenta los numerosos viajes realizados a lo largo de su trayectoria, ¿se interesó por la arquitectura vernácula?

Obra propia (arquitectónica y literaria): En su obra construida, ¿ podemos establecer vínculos de causalidad entre arquitecturas vernáculas estudiadas por él y su obra construida? Y, en su obra escrita, ¿se refiere a este tipo de arquitectura? y, si es así, ¿en qué términos?

\subsection{Contexto de la investigación-limitaciones impuestas}

- Límites temporales: La actitud de Le Corbusier hacia la arquitectura vernácula no fue la misma a lo largo del periodo estudiado (1904-1939). Dicho periodo se establece entre dos hitos, el inicio de su formación de cuatro años con L'Eplattenier en los "Cursos Superiores de Decoración" (1904) de La Chaux-de-Fonds, y la interrupción temporal de su actividad con el comienzo de la Segunda Guerra Mundial (1939). Durante este periodo observamos una continua evolución, desde las primeras lecciones de juventud hasta sus proyectos de los años 30 en Argel, en la que podemos establecer hitos que nos permiten determinar una transformación en su actitud y pensamiento, en el modo de percibir lo vernáculo y cómo lo asume y lo traslada a su obra. La selección de estos hitos nos permite establecer cuatro periodos, siguiendo un orden cronológico. No obstante, el interés por lo vernáculo y la evidencia en su obra continuó más allá de la década de los 30. Cabría citar algunos proyectos, como el realizado en Roquebrune y Sainte-Baume en la Costa Azul (1948), las casas Jaoul en Neuilly (1953), o los proyectos de vivienda para Chandigarh, junto a Pierre Jeanneret, Maxwell Fry y Jane Drew, a partir de la década de los 50. 
- Límites geográficos-urbanos: La actividad e influencia de Le Corbusier no puede ser reducida a un lugar concreto. Por este motivo no establecemos límites, sino que situamos y describimos los lugares en los que existen evidencias de relación del arquitecto con lo vernáculo durante el periodo considerado.

- Volumen de estudio: La elección de los casos de estudio viene determinada por las evidencias encontradas en torno a cuestiones tipológicas, decorativas, espaciales, técnicas o urbanas que conciernen a lo vernáculo y que consideramos significativas. Esta selección no exime que pueda ser un hecho cuestionado, dado la extensión de periodo estudiado y la intensa actividad de Le Corbusier. Aun siendo conscientes de ello, consideramos que, en caso de haber optado por incluir casos similares, complementaría nuestro discurso general, siguiendo la misma línea argumental y dando lugar a conclusiones similares.

Al ser un estudio histórico, por tanto, eminentemente teórico, se desarrolla en dos etapas: en una primera etapa de investigación se analiza la bibliografía específica publicada principalmente en las últimas décadas, como consecuencia de una actitud revisionista del Movimiento Moderno. En la segunda etapa de estudio se recurre a fuentes originales que han sido utilizadas para construir los textos anteriores, y que constituyen en la mayoría de los casos un modo de matizar los conocimientos recibidos, o suponen el descubrimiento de nuevos datos, e incluso de nuevas fuentes que permiten profundizar el estudio en su conjunto. En esta segunda etapa se recurre, principalmente, a la consulta de archivos y fondos documentales de la Fondation Le Corbusier.

La propia obra de arquitectura constituye otra fuente documental en sí misma. Ha sido necesario visitar algunas de las obras aquí expuestas con la intención de elaborar un material de estudio propio -fotografías, apuntes, levantamientos- que ayude en nuestro análisis.

\subsection{Objetivos}

El objetivo principal de la investigación es determinar el papel que desempeñó lo vernáculo en el pensamiento y obra de Le Corbusier, en un periodo en el que se establecieron las bases de la arquitectura moderna y en el que, como es sabido, ejerció una notable influencia.

El segundo objetivo es identificar el modo en que Le Corbusier asume lo vernáculo y lo traslada a su obra para establecer distintos periodos en su evolución personal (regionalismo, apertura a nuevos lenguajes, purismo, brutalismo), a partir del análisis cronológico de los hechos analizados, desde la infancia hasta la conformación de un lenguaje arquitectónico propio.

El cambio de su nombre de pila, Charles-Édouard Jeanneret a Le Corbusier lo realizó durante su estancia en París en el año 1920

\section{Primera época: la forma- ción junto a L'Eplattenier y el regionalismo del Jura (1904-1908)}

La pequeña localidad natal de Charles-Édouard Jeanneret, La Chaux-de-Fonds, está ubicado en el alto valle de la cadena del Jura, rodeado por montañas $y$ bosques. A finales del siglo XIX y principios del XX estaba muy extendida la visión de la naturaleza como un escape espiritual a la civilización industrial. Jeanneret tuvo un estrecho vínculo con la naturaleza del Jura desde su infancia, pues su padre era presidente del Alpine Club y pasaba los fines de semana dando largos paseos en las montañas de la región, donde construyó refugios mínimos para condiciones extremas. Analizando las entradas del diario del padre del joven, Vogt (1998) muestra cómo veía aquellas condiciones como una vuelta rousseauniana a la vida natural.

Jeanneret dejó constancia de este interés por el paisaje y la construcción tradicional local en las acuarelas de graneros o establos que le servían como modelo pictórico.

Fue en 1904 cuando inició su formación de cuatro años con el maestro Charles L'Éplattenier, en los "Cursos Superiores de Decoración". La relación entre ambos fue importante para profundizar en el conocimiento de la arquitectura y el paisaje del Jura. Las enseñanzas de L’Éplattenier fueron encaminadas a la formación de una cultura regionalista en la École d'Art. Encajaba dentro de esa tendencia de comienzos del siglo XX en la que se veía la naturaleza como un escape espiritual de la civilización industrial. Para ello les inculcó a sus alumnos la lectura Lacustres Habitations de Frédéric Troyon, que proporcionaba una visión global de la cultura y la arquitectura local desarrollada en contacto con el agua en algunos lagos suizos, como por ejemplo los lagos de Zurich o de Biel. El libro estaba narrado desde un punto de vista retrospectivo, en una época de entusiasmo por el discernimiento de un periodo anterior desconocido de la región suiza. Vogt (1998) concluye que CharlesÉdouard Jeanneret leyó las obras de Frédéric Troyon, y lo hizo durante sus años iniciales de formación en La Chaux-de-Fonds. Su conclusión se fundamenta en la comparación entre un fragmento de la obra de Troyon, Lacustres Habitations, y los bocetos de Le Corbusier para el proyecto de la Liga de las Naciones.

Guiado por L'Éplattenier, leía también la obra de Henry Provensal (Brooks, 1997) L'Art de demain, lo que le animaba a relacionar la arquitectura con las formas naturales del mineral cristalizado y seguir las leyes de la geometría, los números, la unidad, la armonía. La abstracción geométrica y las estructuras subyacentes de plantas y fósiles las encontró mientras copiaba las ilustraciones de Owen Jones en su obra Grammar of Ornament y estudiaba a Eugène Grasset, Méthode de Composition Ornemental (Brooks, 1997). Los abetos y la piedra caliza, tan cotidianos en aquella región, fueron motivos utilizados por Jeanneret en sus dibujos (Figura 1) 

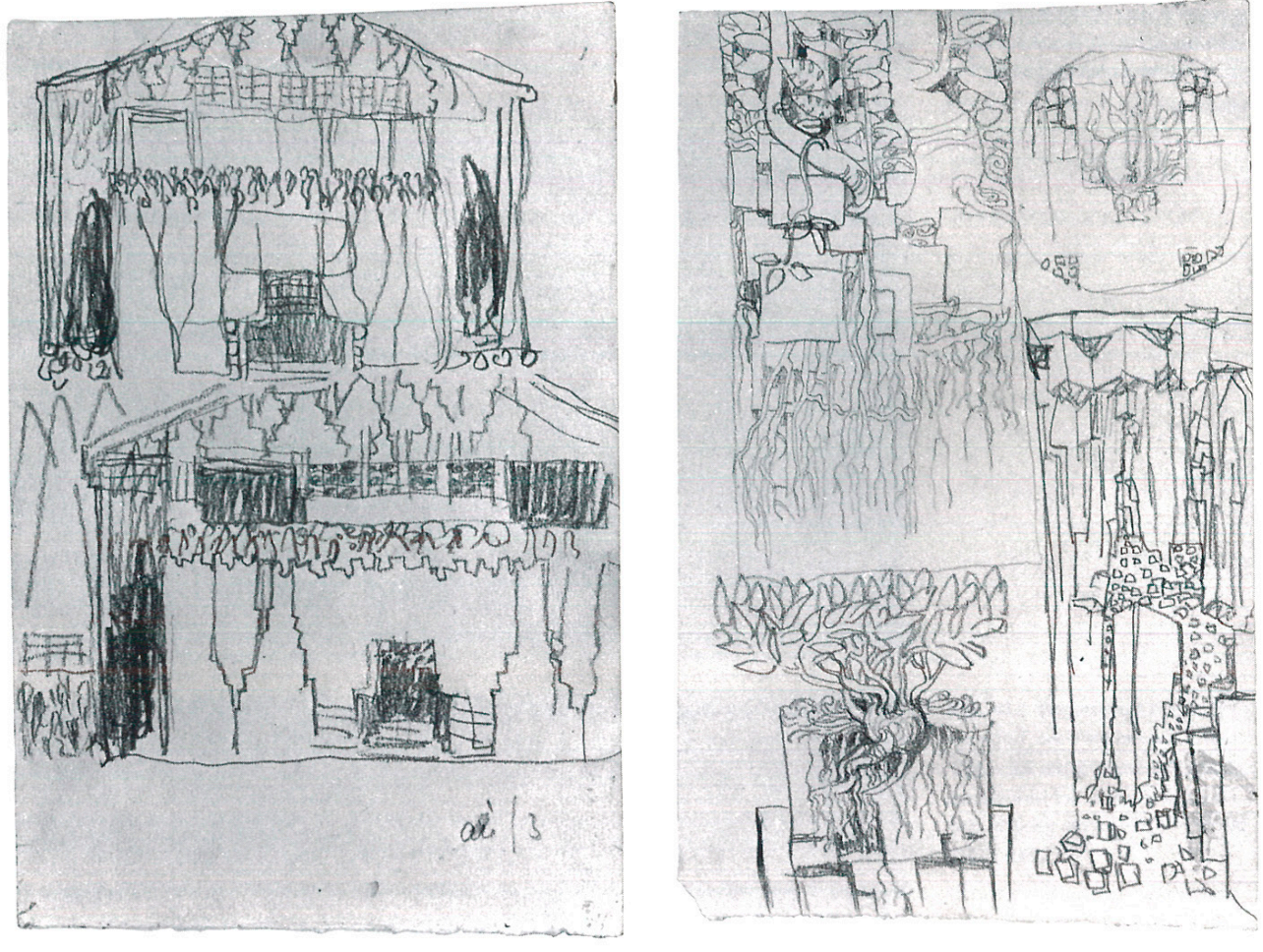

Figura 1: Le Corbusier. Dibujos decorativos para fachadas inspirados en elementos de la naturaleza como vegetación, rocas, tierra, etc.

Fuente: Brooks (1997)

El propio Jeanneret, reconoció que L'Éplattenier fue un "excelente profesor y un verdadero hombre de los bosques [...] nos convirtió en hombres de los bosques [...] así que yo también fui regionalista durante mucho tiempo [...] durante más de diez años compusimos una especie de himno a nuestra tierra porque mi maestro había dicho: 'Vamos a renovar la casa y a revivir las artes y los oficios perdidos"' (Vogt, 1998, p.184).

Esta inclinación por la corriente regionalista le llevó a despreciar la arquitectura de Otto Wagnery la Sezession en su viaje a Viena en 1908. Viena era el foco arquitectónico, como lo había sido antes Inglaterra y el Arts and Crafts, Bélgica con el Art Nouveau o Glasgow con trabajos de Charles Rennie Mackintosh. Sin embargo, rechazó la vanguardia en su primer contacto. Le desagradaba la pureza y lo refinado de su arquitectura y la descalificaba repetidamente en sus cartas a L'Éplattenier (por ejemplo, la carta que le envió el 26 febrero de 1908, publicada por Dumont (2006).

Todas estas ideas motivadas por las enseñanzas de L'Éplattenier cristalizaron en las villas Fallet (1906), Stotzer y Jacquemet (1907-1908) que Jeanneret construyó en La Chaux-de-Fonds.

Jeanneret elaboró los planos de la Villa Fallet y supervisó la obra junto a René Chapallaz (Figura 2). La vivienda fue el resultado de los estudios que realizó con maquetas de arcilla y que podemos observar en una imagen conservada en la Fondation Le Corbusier. Desde un punto de vista formal la vivienda resulta un volumen compacto con una cubierta principal a dos aguas con una pendiente pronunciada con ángulos comprendidos en torno a los 50 . Sus faldones vuelan sobre el paramento vertical para proteger las ventanas y balcones de los niveles inferiores. La base es de grandes sillares de piedra caliza y el piso superior se encuentra revestido por madera labrada y estuco.

Para autores como Stanislaus von Moos y Brooks (1997), la fuerte pendiente de la cubierta, su estructura a dos aguas o la compacidad de la edificación responden a un revival medieval. Las referencias al chalé suizo aparecen en los elementos estructurales sin revestir y ricamente decorados, así como los voladizos de la cubierta sobre los balcones inferiores que forman los faldones y el peto. Observamos, por tanto, el empleo de clichés que se alejan de los aspectos meramente vernáculos de la arquitectura del Jura para buscar un estilo regionalista dentro de la corriente del Art Nouveau. Este último aspecto se aprecia especialmente en la decoración de sus superficies y carpinterías.

En esta vivienda puso en práctica todos aquellos ejercicios de abstracción geométrica inculcados por L'Éplattenier aplicándolos en los revestimientos y la decoración. Por ejemplo, se inspiró en los estratos naturales de la roca para la construcción de los muros de mampostería. Establecía así un vínculo visual con el entorno montañoso del Jura, fuertemente influenciado por la poética de 
John Ruskin y Owen Jones ${ }^{3}$. La mayor parte de motivos decorativos que podemos observar hacen referencia al abeto, símbolo regionalista del Jura. Los encontramos en la madera labrada del hastial, dinteles sobre puertas y ventanas, los revestimientos de madera del interior, o la forja de balcones y terrazas.

\section{Segunda época: la apertura a nuevos lenguajes (1908-1918)}

Durante este segundo periodo Jeanneret profundizó en el conocimiento de la arquitectura vernácula de Jura. Habitó en la habitación de una antigua granja situada en el Monte Cornu entre noviembre de 1909 y abril de 1910. Era su lugar de residencia durante los periodos en que residía en La Chaux-de-Fonds, entre viajes. También residió en un antiguo caserío llamado "Le Couvent" donde vivían sus amigos Octave Matthey y Eric de Coulon (Figura 3). Alquiló el piso superior y lo remodeló, enluciendo los muros y pintándolos de blanco y abriendo en el muro exterior una ventana grande. Aunque sus amigos abandonaron la casa con la llegada del invierno, Jeanneret estuvo viviendo en esta antigua granja cerca de un año. A pesar de que las condiciones no fueran excesivamente confortables, Jeanneret reconoce su especial predilección por este tipo de arquitectura en las cartas conservadas de este periodo en la Fondation Le Corbusier.

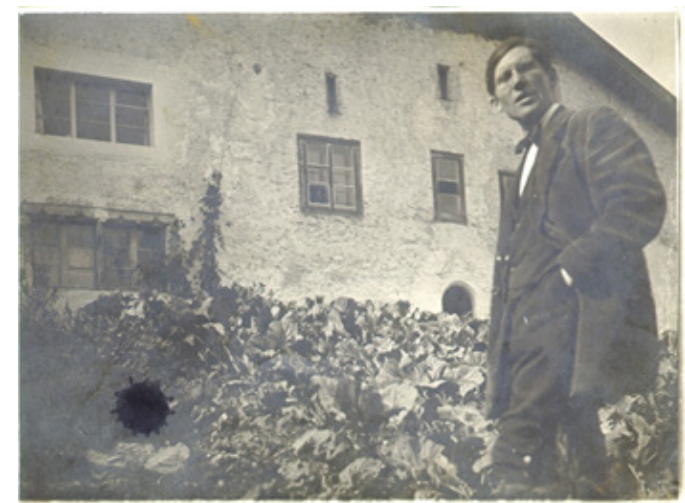

Figura 3: Le Corbusier en la granja de Le Couvent, La Chaux-du-Fonds

Fuente: Fondation Le Corbusier (L4-1-1-001)

Para él, el espacio más simbólico era la chambre du tué, o habitación del fuego, por el significado implícito que tenía de seguridad, protección e intercambio social (Figura 4):

Ese sitio me gusta como un loco, vivo en él como un ermitaño, Octave Matthey vive en la planta baja, y hay también una cocina colosal de la cual la chimenea hace de techo; pongo la sección para que pueda imaginarla y también para que se pueda instalar el próximo invierno para cuando venga (Fondation Le Corbusier, FLC E2-6-137-003)

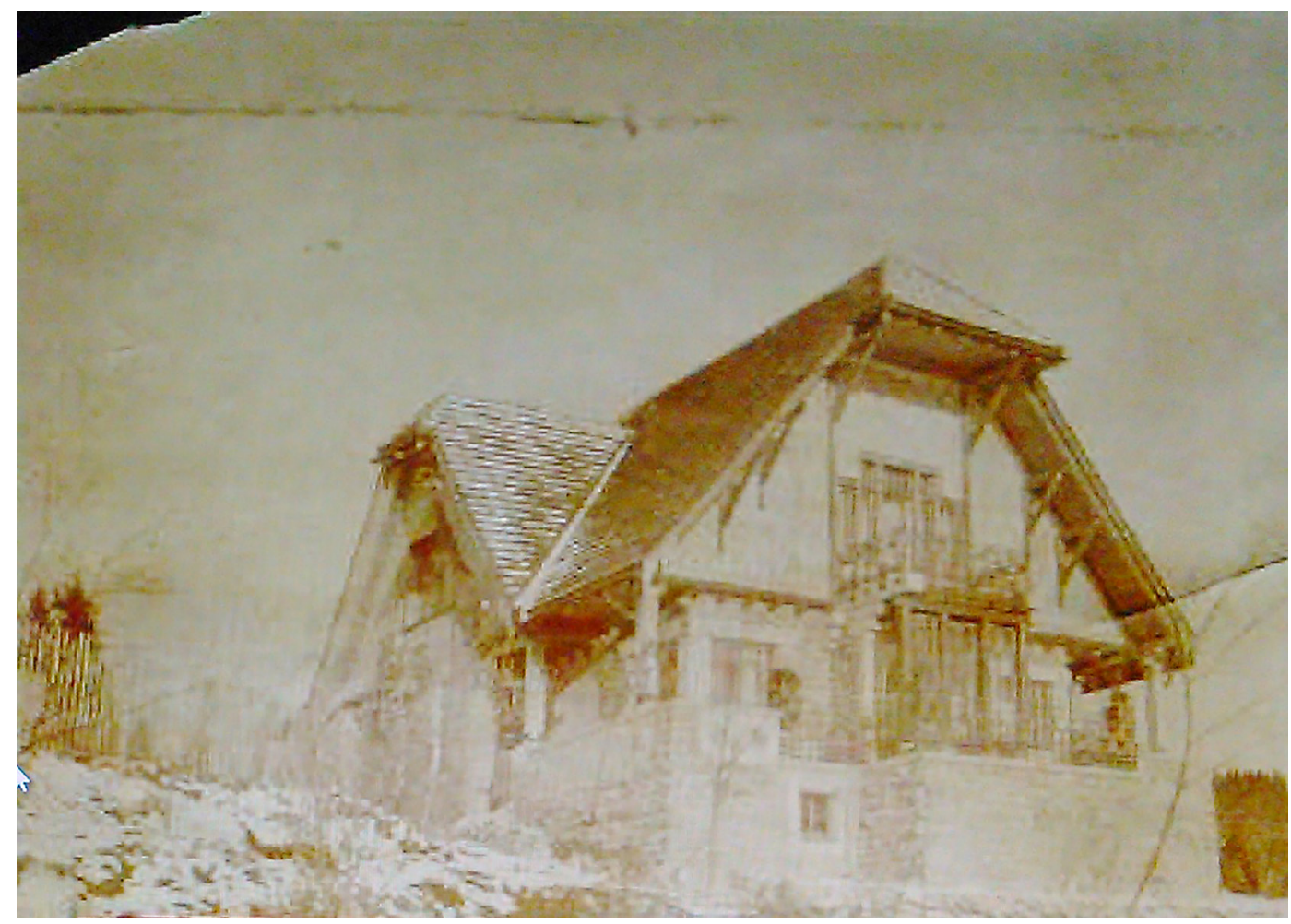

Figura 2: Vista exterior de la Villa Fallet

Fuente: Fondation Le Corbusier (L3-16-4)

3 Le Corbusier leyó a Ruskin, tal y como refleja la obra Les Matins a Florence conservada en la Fondation Le Corbusier y firmada por él mismo. 


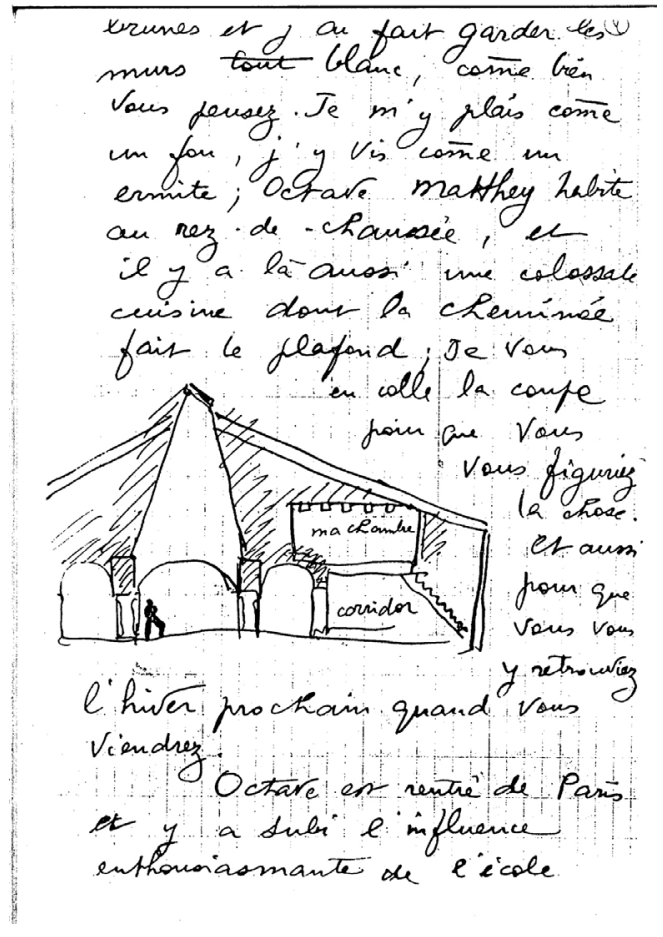

Figura 4: Le Corbusier. Esquema de la granja en la que especifica la ubicación de "su habitación" y la sala central, en la carta que escribió el 18 de diciembre de 1911 a "Klip" (August Klipstein)

Fuente: Fondation Le Corbusier (E2-6-137-003)

Las granjas del Jura también le servían de modelo para sus acuarelas y fotografías, como las que realizó en el verano de 1910. En sus vistas incluía generalmente la chimenea truncada según la inclinación de la cubierta. Su interés por este tipo de construcciones lo compartió con William Ritter en una carta escrita el 6 de septiembre de 1910:

Desde la época de las antiguas casas de campo del siglo XVIII nosotros tenemos falta de una verdadera tradición en el arte. Sin embargo, estas dulces, espléndidas y viejas casas me proporcionan una medida de lo que podemos hacer si queremos (Brooks, 1997, p. 227)

Pero lo que diferencia realmente este periodo del anterior es el acceso al conocimiento de arquitecturas vernáculas de otras regiones como consecuencia del contacto con diversos personajes de la cultura centroeuropea. Fue el caso de William Ritter, escritor, crítico de arte y pintor, y una figura relevante de la cultura suiza de principios del siglo XX. Su obra literaria se nos presenta como una directa traducción de sus preocupaciones estéticas y culturales, centradas básicamente en la defensa de los valores de lo popular y de las tradiciones vernáculas, ya en vías de desaparición ante el avance maquinista. Para él, el progreso de la modernidad debía hacerse de un modo mesurado y se debían tender lazos con todo el saber ancestral y atemporal de dichas tradiciones (Calatrava, 2012). El propio Ritter le recomendó la lectura de Cyngria-Vaneyre, introduciéndolo en las teorías raciales de la suiza romanda, así como en las obras de Schultze-Naumburg, que defendía la arquitectura vernácula alemana como base formal desde la que partir hacia una nueva arquitectura, en un contexto romántico de defensa de lo artesanal y de creciente sentimiento nacionalista, que derivaba en un profundo sentimiento anti-mediterráneo. Sabemos que Le Corbusier leyó Kulturarbeiten a través de las cartas que envió a L'Éplattenier (carta enviada el 16 de enero de 1911 (FLC E2-12 54-038)) y por las citas de La construction des villes y su relación con los textos e imágenes del volumen 4 de Kukturarbeiten. Las anotaciones de Jeanneret en el libro de Cyngria Vaneyre, Les Entretiens de la villa du Rovet; essais dialogués sur le plastiques en Suisse romande, nos indican que concluyó su lectura el 22-23 de noviembre de 1910, tal y como refleja en otra de las inscripciones que aparecen en el texto (ejemplar conservado en la Fondation Le Corbusier).

Estas lecturas las compaginó con la colaboración con Peter Behrens (1910-1911) y los hermanos Perret (1908 1909), así como su asistencia al congreso del Deutscher Werkbund, celebrado en Berlín (1910). Estas experiencias le abrieron nuevos horizontes arquitectónicos y le permitieron conocer y ampliar sus conocimientos sobre el clasicismo y la armonía de la proporción, el mundo de la industrialización y la estandarización, el descubrimiento de las cualidades del arte y la arquitectura popular de otras regiones.

En 1911 abandonó su residencia en la granja para visitar más de 12 ciudades alemanas con el objetivo de terminar su estudio de las artes aplicadas del país gracias a la beca que le había conseguido Charles L'Éplattenier. Tras aquel periplo, Le Corbusier comenzó su Voyage d'Orient en el mes de mayo, acompañado de Auguste Klipstein, estudiante de historia del arte en la Universidad de Múnich, que por aquella época estaba terminando su tesis doctoral (Zaknic, 2017). Se dirigieron a las costas del Adriático con rumbo a Turquía, Grecia e Italia, para volver a su ciudad natal de La Chaux-de-Fonds el 1 de noviembre de 1911. Aquel viaje supuso la adquisición de un amplio abanico de referencias vernáculas que podemos observar en los dibujos y anotaciones de sus cuadernos y que, como veremos, incorporó de una u otra manera a su regreso y en la década posterior. Le Corbusier escribió al respecto, en defensa de lo popular y de las tradiciones vernáculas, que no conocía nada más "lamentable" que la obsesión por renegar de las tradiciones con el único fin de crear lo "nuevo' ansiado", identificando al campesino como un artista "salvaje" que crea obras llenas de "torpezas y barbarismos" pero que esa torpeza se aparece bella. El arte del campesino era para Jeanneret "una impresionante creación de sensualismo estético" (Le Corbusier, 1993, p. 29).

Debemos entender Le voyage d'Orient como un paso más en su formación, donde pudo experimentar en primera persona algunos de los consejos y lecciones aprendidas hasta ese momento, confirmando unos y descubriendo otros nuevos. Durante su transcurso, Le Corbusier anotó y dibujó todo cuanto le atraía de los parajes y las arquitecturas que visitaba. Para autores como Schubert (2002) durante aquellos primeros meses y hasta la llegada a Turquía, la mencionada obra de SchultzeNaumburg, Kulturarbeiten, le proporcionó las claves para la identificación, la simplificación y la grabación de las aldeas que visitaba, siguiendo los consejos de Ritter, como lo muestran las fotografías que tomó de la arquitectura vernácula y las referencias a la citada obra. 
En Turquía fueron otros aspectos los que le llamaron la atención: en concreto, la unidad formal de Isfaham ${ }^{4}$ y la ciudad de Estambul, gracias al diseño modular de una "geometría elemental" de elementos cúbicos que hacían de la ciudad una obra maestra del urbanismo (Çelik, 1992, p. 63). Estambul supuso un punto de inflexión en lo que se refiere a la atención que le había prestado a elementos vernáculos como pérgolas, tapias, patios, huecos en fachada, etc. Tras su paso por Turquía se centró, principalmente, en la arquitectura clásica griega e italiana, con todo lo que ello supuso como referencias conceptuales y formales que aflorarían años más tarde en proyectos de distinta naturaleza, tal y como ha sido estudiado por diversos autores (Pauly, 1987).

En los textos y dibujos que realizó podemos extraer referencias que constituyen lo que unos años después formó parte de su repertorio formal. Uno de los elementos fue la chambre d'eté -patio o habitación de verano- que pudo ver en las viviendas de Serbia y Hungría, encaladas y con patios rodeados por altas tapias y galerías en su perímetro. También dibujó otras casas con patio en la aldea búlgara de Kazanlûk (Figura 5) y dibujos de interior en los que destaca la separación entre estructura y cerramiento.

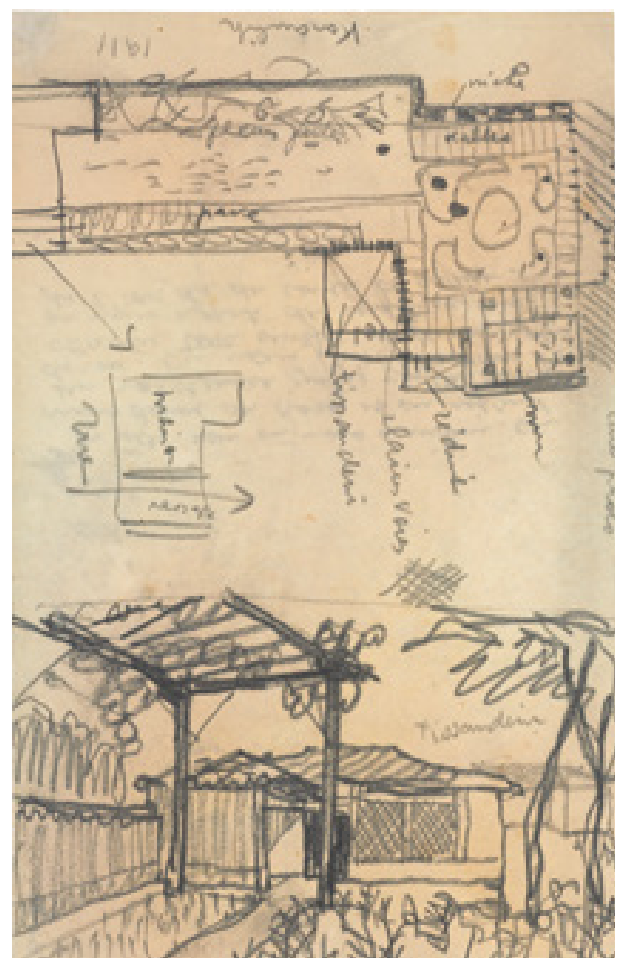

Figura 5: Le Corbusier. Dibujo de patio y pérgola en una vivienda en Kazanlûk (Bulgaria)

Fuente: Fondation Le Corbusier (FLC-DE-6072)

Estas imágenes le recordaba a Le Corbusier (1993, p. 35) la Cartuja de Ema que, combinada con las pequeñas ventanas que encontró en los muros del cementerio de Eyüp en Estambul, le sirvió, según Brooks (1997) de precedente para la casa Jeanneret cerca de Vevey (1924)

4 Según se deduce de la carta enviada a William Ritter el 10 de Septiembre de 1910 (R3-18-107-008, Fundación Le Corbusier). y la Villa Savoye en Poissy (1929). Tanto Brooks (1997) como Passanti (1997) coinciden en que además de la chambre d'etè que dibujó en los patios de las casas de Hungría, la fenêtre en longueur que dibujó en el interior de una casa de Tirnovo es una importante fuente para la configuración de la ventana horizontal de la villa Saboye (1928). Respecto al color blanco de su arquitectura, Le Corbusier (1993, pp. 68-70) volvió a dejar constancia en Le voyage d'Orient al referirse a Tirnovo.

Si bien estos aspectos aflorarían en la década posterior, en los proyectos de este segundo periodo se aprecian diferencias significativas respecto de los proyectos de su primera época, introduciendo elementos nuevos y depurando un lenguaje a medida que se acercaba a la década de 1920. Por ejemplo, en el proyecto para villa Jeanneret-Perret observamos una nueva iconografía (Figura 6) que aparece en los dibujos de los cuadernos del viaje de Oriente, tal y como se desprende de la carta que escribió a Klipstein el 18 de diciembre de 1911 para el proyecto de la vivienda de sus padres:

Envíame, tan pronto como sea posible, cualquiera de los negativos o las impresiones de bromuro de los Balcanes, Knajewatz, Radojevaz, los monasterios de Bucarest, Kasalink y sobre todo la terraza de Skite Sainte-Anna. Las necesito para la villa que estoy diseñando en este momento (Fondation Le Corbusier, FLC E2-6-137).
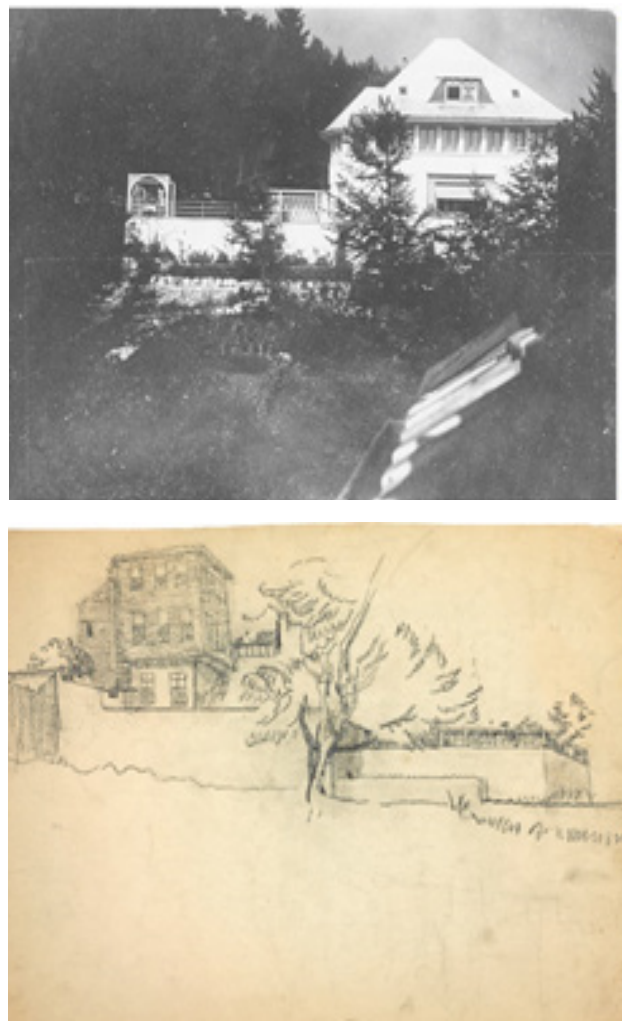

Figura 6: Fotografía de la Villa Jeanneret-Perret en la que se aprecia la vivienda, el muro de contención, el jardín y la pérgola y el dibujo realizado durante el Viaje de Oriente con una estructura similar en la organización de la vivienda y los espacios de alrededor

Fuente: Fondation Le Corbusier (L3-16-16-001 y D-1930-R) 
Su actividad se concentraba no solo en proyectos de obra nueva como el anterior sino en la reforma de edificios existentes, como fue el caso de la granja conocida como La maison hantée. De este modo las granjas se convertían, no solo en un lugar predilecto donde residir, sino en un laboratorio formal que anticipaba el lenguaje arquitectónico de los siguientes proyectos. Tras la demolición de su cubierta fue a visitarla y poco después dibujó algunos bocetos con lo que planeaba adaptarla a una vivienda moderna. Aprovechando la ausencia de la cubierta, planteó una cubierta plana ajardinada que transformaba el volumen de la casa en un volumen rectangular y al que le añadía una escalera exterior de acceso a la terraza, respetando el volumen delimitado por los antiguos muros (Jung, 1966).

Esta evolución formal de su arquitectura concluye con los sistemas Dom-Ino al año siguiente de visitar La Cité moderne y conocer el trabajo de Tony Garnier ${ }^{5}$. En este proyecto afloran aspectos de la obra de este y otros ya analizados del primer periodo, como estructuras sobre pilotes que Vogt (1998) ha relacionado con los sistemas constructivos propios de arquitecturas lacustres. E propio Le Corbusier (1972) afirmó en la conferencia de 10 de octubre de 1929 en la Facultad de Ciencias Exactas: "Mis ideas revolucionarias están en la historia, en toda época y en todos los países. (Las casas de Flandes, los pilotes de Siam o de los lacustres, la celda de un fraile cartujo en plena beatificación)" (Le Corbusier, 1999 p. 120). Se trataba de un sistema que constituía una solución unitaria que permitía resolver una serie de cuestiones formales y constructivas que más tarde se le plantearían a Le Corbusier en la década de 1920, y que están relacionadas con los discursos acerca del "tipo" extraídos del debate del Deutscher Werkbund alemán (nuevos materiales, estandarización, construcción en serie, el concepto de identidad colectiva en la producción masiva industrial y los tipos vernáculos, etc.)

Tras la presentación del sistema Dom-Ino, Jeannere realizó otras propuestas. Una de ellas fue la casa para Felix Klipstein, hermano de Auguste Klipstein, que iba a construirse en Laubach, Alemania. Para este proyecto buscó referencias mediterráneas en las anotaciones de sus cuadernos del viaje a Oriente. El propio Klipstein eligió las imágenes más sugerentes en las 14 acuarelas, 8 láminas de mayor tamaño, 175 dibujos y 4 cuadernos de bocetos que Jeanneret le mostró.

Junto a esta fuente de referencias, Jeanneret mencionó el deseo de recrear el ambiente de las casas rurales de la región francesa de Dordogne. No sabemos con certeza si la arquitectura de aquella región pudo inspirar a Le Corbusier, aunque tenemos constancia de una postal que envió a sus padres en la que aparece fotografiado una antigua granja en Sarliac (Dordogne) y donde podemos leer: "una región donde hacen arquitectura real, buenas casas en las que vivir" (Fondation Le Corbusier, X1-11 $144-005)^{6}$.

${ }^{5}$ El vínculo de su arquitectura con la tradición mediterránea ha sido estudiado por autores como Josep María Montaner o Jean Louis Cohen.

${ }^{6}$ No se conoce la fecha de la tarjeta postal. En ella Le Corbusie escribió "Toulouse viernes". La imagen de la postal la utilizó en varios escritos como La ville radieuse: éléments d'une doctrine d'urbanisme pour l'équipement de la civilisation machiniste (Le Corbusier, 1964)
En otras villas como la villa Schwob (1916) observamos detalles extraídos directamente de la tradición vernácula suiza, como es el alero de terminación de la cubierta plana (Brooks, 1997). La cubierta avanzaba sobre el plano de fachada mediante un ancho alero que la protegía de los agentes meteorológicos. Passanti (2002) hace alusión a la antigua casa romana, en concreto la casa de Diomedes que admiró en Pompeya, como referencia para dicha villa. Se cierra a la calle, se abre al jardín y al paisaje, y se organiza en torno a un núcleo central o atrio.

En el caso de su proyecto de las casas de la fábrica de relojes Duverdrey y Bloquel en Saint Nicolas d'Aliermont, existen evidencias en sus estudios preparatorios: analizó los materiales, los tipos de cubierta, las ventanas y el resto de características de la arquitectura vernácula del lugar (Figura 7).

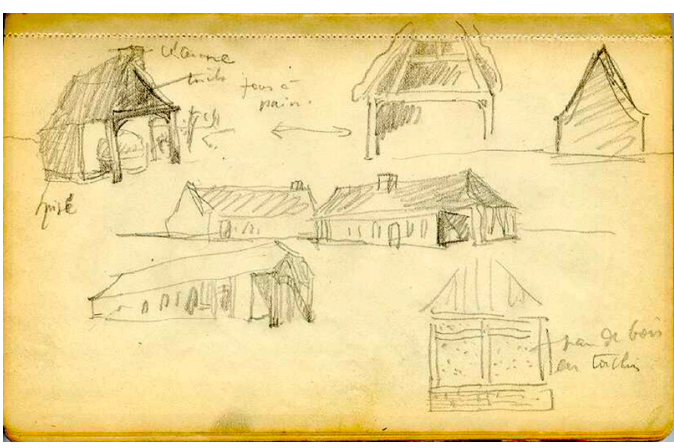

Figura 7: Le Corbusier. Dibujos preparatorios para e proyecto de las casas de la fábrica de relojes Duverdrey y Bloquel, Normandía, 1917

Fuente: Fondation Le Corbusier (W1-1-166)

Trascurridos cinco años de presentar el sistema Dom-Ino, en 1919 Le Corbusier proyectó y patentó de nuevo un sistema de construcción en serie conocido como sistema Monol. Se trataba de un sistema de cubrición que algunos autores han relacionado con sus experiencias en Marruecos y sus conocimientos de la arquitectura persa. El uso de la bóveda de cañón recuerda los trabajos de Perret en Marruecos, concretamente en Casablanca, realizados unos años antes. Según Brooks (1997), este tipo de techo abovedado se puede ver también en Koum, como ilustración de Dieulafoy en L'Art Antique de la Perse, obra cuidadosamente estudiada por Jeanneret.

\section{Tercera época: la arquitectura} como expresión de la época (19181927)

Auguste Perret promovió en 1918 el encuentro entre Le Corbusier y el pintor Amédée Ozenfant, quien le introdujo en los círculos artísticos parisinos y promovió la fundación del L'Esprit Nouveau. Durante esa época, Le Corbusier destacó como un prolífico autor con diez títulos publicados que constituyen un primer compendio en el que proclama lo esencial de su pensamiento. En uno de ellos, Une Maison-Un Palais, manifestaba su

y en el artículo "Vers la 'Ville Radieuse'. Une nouvelle ville remplace une ancienne ville," (Le Corbusier, 1931). 
admiración por la casa-tipo de la arquitectura vernácula que satisfacía en grado sumo los principios de economía y claridad geométrica (Le Corbusier, 1989). En Précisions, Le Corbusier (1999) reflejó el vínculo de causalidad entre las experiencias previas durante su etapa de formación y algunos de sus proyectos más importantes de la década de 1920. Es el caso del viaje a la Cartuja de Ema de 1907 y el concepto de "célula habitacional", y sus vínculos con los "inmuebles-villas". Cabría citar aquí las conclusiones que apunta Vogt (1998) acerca de la relación entre las "células habitacionales" y las estructuras sobre pilotes que aparecen en estos sistemas constructivos en relación al enorme paralelismo entre los dibujos de Le Corbusier en Oeuvre complète de las células espaciales y los dibujos de las cabañas de Irlanda, como superposición de células individuales, así como las propuestas de Maison Citrohan entre 1922 y 1927, en concreto la que proyectó en la Costa Azul al borde del mar (Le Corbusier, 1929).

En el caso de la Villa Savoye (1929), una de sus obras más paradigmáticas, autores como Brooks (1997) y Passanti (1997) coinciden en que elementos como la fenêtre en longueur, que dibujó en el interior de una casa de Tirnovo durante su viaje de Oriente, constituye una importante referencia para la configuración de la ventana horizontal de la misma. Le Corbusier hace alusión a otros modelos vernáculos, en concreto árabes, en la conformación del concepto promenade architecturale de la casa (Figura 8):

La arquitectura árabe nos proporciona una enseñanza preciosa. Se aprecia caminando a pie; andando, al desplazarnos vemos desplegarse las leyes de la arquitectura. Es un principio contrario al de la arquitectura barroca que está concebida sobre el papel, en torno a un punto teórico. Yo prefiero la enseñanza de la arquitectura árabe. En esta casa, se trata de una verdadera promenade architecturale, que ofrece aspectos que varían constantemente, inesperados, a veces sorprendentes (Le Corbusier, 1934, p. 24).

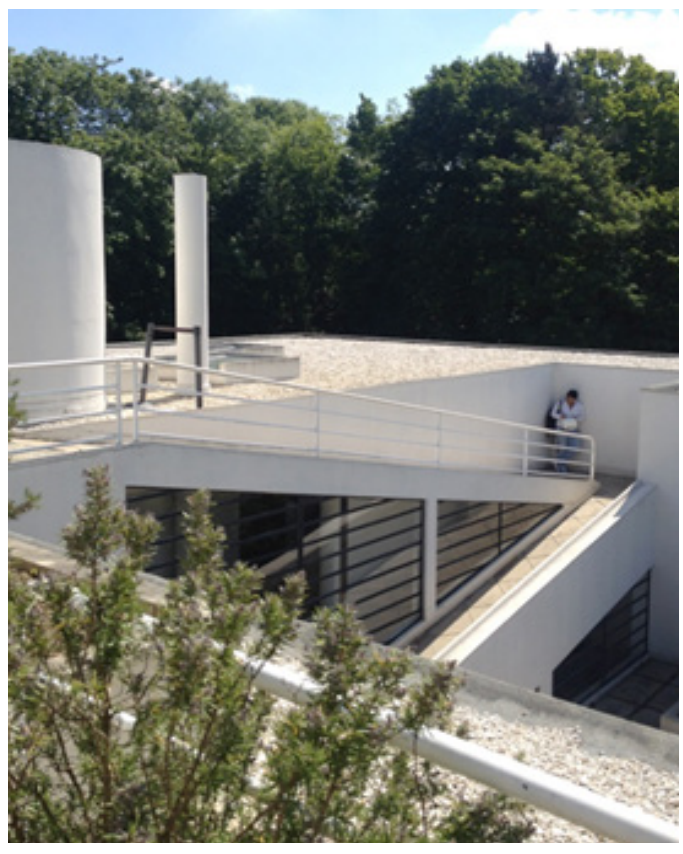

Figura 8: Vista de la Villa Savoye desde la cubierta. Recorridos posibles, Poissy, Francia Fuente: Imagen del autor (2014)
Otro de sus proyectos, La petite maison, construida para sus padres en la orilla del lago Léman, constituye un ejemplo de adaptación bajo un lenguaje moderno de aspectos vernáculos estudiados con anterioridad: aparece el jardín colgante soportado por el muro de contención que había dibujado de la casa turca durante su viaje a Oriente, la pictórica ventana de la chambré d'eté, similar a las del cementerio de Eyüp, cuya libre disposición y forma le permitían entrever las tumbas apretadas bajo los cipreses, estableciendo un filtro visual entre el exterior y el interior (Gresleri, 2002), y también la terraza, que conforma un aspecto cúbico de la casa. Encontramos elementos similares en la intervención principal de Le Corbusier en el jardín de la Villa Berque y Villa Montmorency en Auteuil (1921-1922).

Tanto estos proyectos como su obra escrita, Vers une architecture, nos muestran la reaparición de los conocimientos previos adquiridos, si bien no se trataba de una transcripción exacta de motivos arquitectónicos extraídos como en su primer periodo en La Chaux-deFonds. Se trataba, más bien, y coincidiendo con la tesis de Passanti (1997), de un modelo conceptual que mostraba una relación natural entre la sociedad y sus artefactos, y por tanto entre la sociedad y su arquitectura, como un modelo conceptual que representa la moderna sociedad industrial. Esta actitud situaba a Le Corbusier en la línea de las tesis defendidas por Hermann Muthesius acerca del "tipo arquitectónico" que le ayudó en la búsqueda de una modernidad vernácula en sus casas tipo, a las que atribuía un papel cultural como representación de la sociedad moderna. También lo situaban en la tesis defendida por Paul Schultze-Naumburg, consciente de que las nuevas condiciones defendían la relevancia de los tipos tradicionales que debían adaptarse a los nuevos tiempos.

\section{Cuarta época: los años treinta y la poética de lo vernáculo (1928- 1939)}

Durante este cuarto periodo, que podríamos situar en la década de 1930, Le Corbusier mostró un notable interés por la arquitectura vernácula de las costas francesas y españolas y la arquitectura del norte de África. Este incremento de viajes al Mediterráneo se tradujo en una mayor producción de escritos y dibujos en sus carnets de viajes como consecuencia de los estudios preparatorios para los proyectos que debía afrontar en diversas regiones mediterráneas, en concreto España, Francia, Argelia e Italia. Esta búsqueda por parte de Le Corbusier de una identidad latina fue creciendo a lo largo de la década gracias a su colaboración en las revistas Prelude, Plans, la italiana Quadrante y sus ideas de ejes, que expuso durante el proyecto para Argel y en el IV CIAM, en aguas del Mediterráneo a bordo del Patris II.

Le Corbusier visitó España hasta en seis ocasiones en el periodo que transcurrió desde 1928 hasta 1932. Dejó constancia de su arquitectura vernácula en multitud de ocasiones y ejerció una notable influencia en los arquitectos de la Generación del 25. Por ejemplo, a su paso por Almería (Figura 9) rechazó el academicismo y 
reconoció en su arquitectura popular ciertos aspectos del cubismo:

Cerca del Almería (dirección Málaga), es el primer cubismo con sus prismas y todos los secretos de su color. Nos quejamos que el cubismo sea desesperadamente intelectualizado. iPero no! Está lleno de la sensualidad de la tierra, de las cosas y de los espectáculos. Está arraigado, enrazado, apasionadamente sentido (Fondation Le Corbusier, B7, W1-1-426).

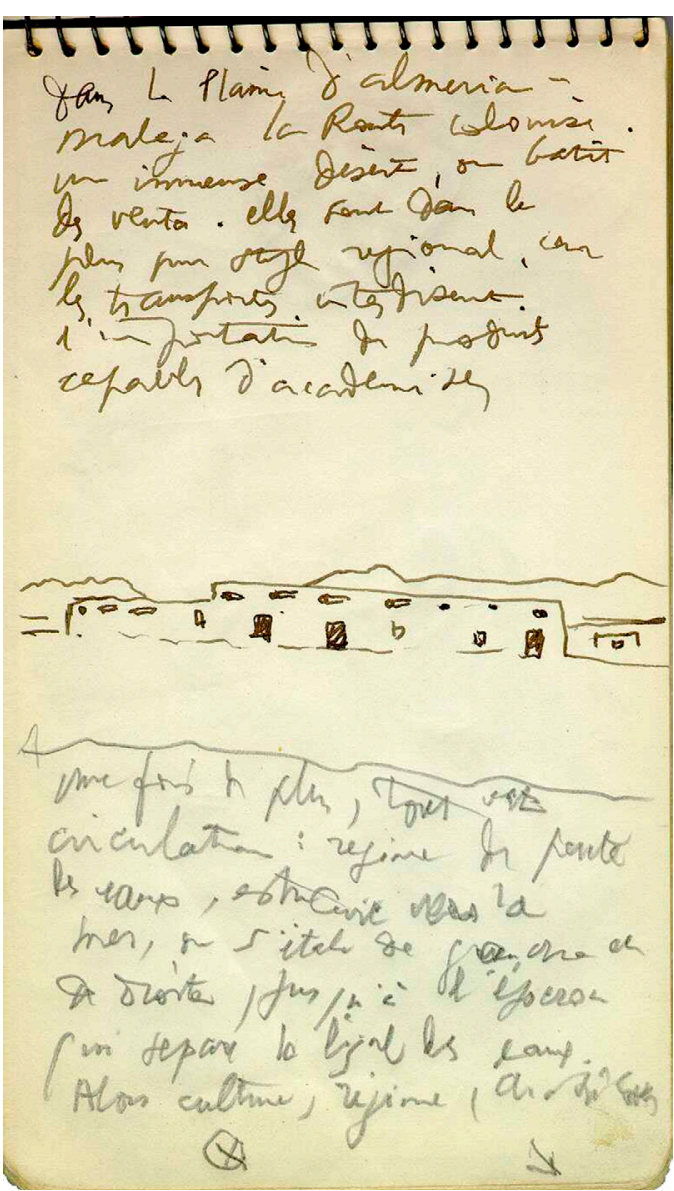

Figura 9: Le Corbusier. Boceto de arquitectura vernácula almeriense, Almería, 1931

Fuente: Fondation Le Corbusier (Cuaderno B7, 1-1-426)

En sus cuadernos de dibujos observamos cómo algunos de los motivos representados fueron utilizados en obras de este periodo y posteriores. Un ejemplo son las bóvedas catalanas que dibujó tomando como referencia la Escuela de la Sagrada Familia de Gaudí en uno de sus primeros viajes por España (1928) (Figura 10) y que utilizó en proyectos como la casa de fin de semana de La Celle-Saint-Cloud (1935), la residencia Peyrissac en una propiedad agrícola de Cherchell (1942), el proyecto de Sabaudia, las casas Jaoul en Neuilly (1953) o el proyecto de Roquebrune y Sainte-Baume en la Costa Azul (1948).

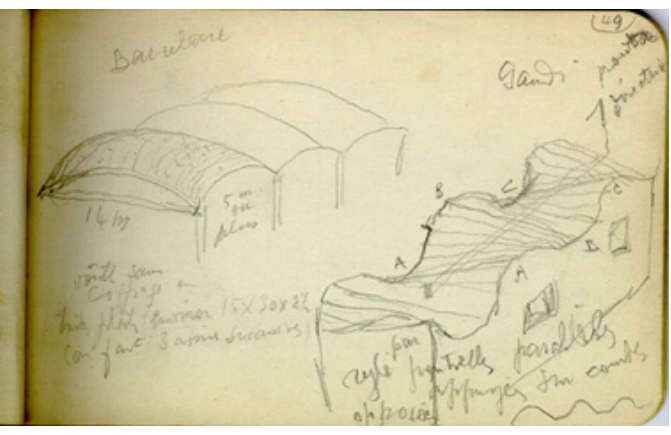

Figura 10: Le Corbusier. Dibujo de bóveda catalana en su visita a Barcelona, 1928

Fuente: Fondation Le Corbusier (Carnet W1-700-001)

España fue la antesala de lo que posteriormente descubriría en Argelia. Allí recorrió las aldeas de M'Zab sobrevolando la región y adquiriendo una visión general de su estructura urbana. A nivel arquitectónico estudió muchos de los aspectos de la arquitectura árabe de Ghardaïa, Ben-Isghem y Vézelay. Le preocupaba la organización de la vivienda en torno al patio, su composición volumétrica, el color y las cualidades de sus espacios, las dimensiones de los muros, la atmósfera interior de las viviendas, el ambiente fresco y escasamente luminoso de sus interiores (Figura 11).

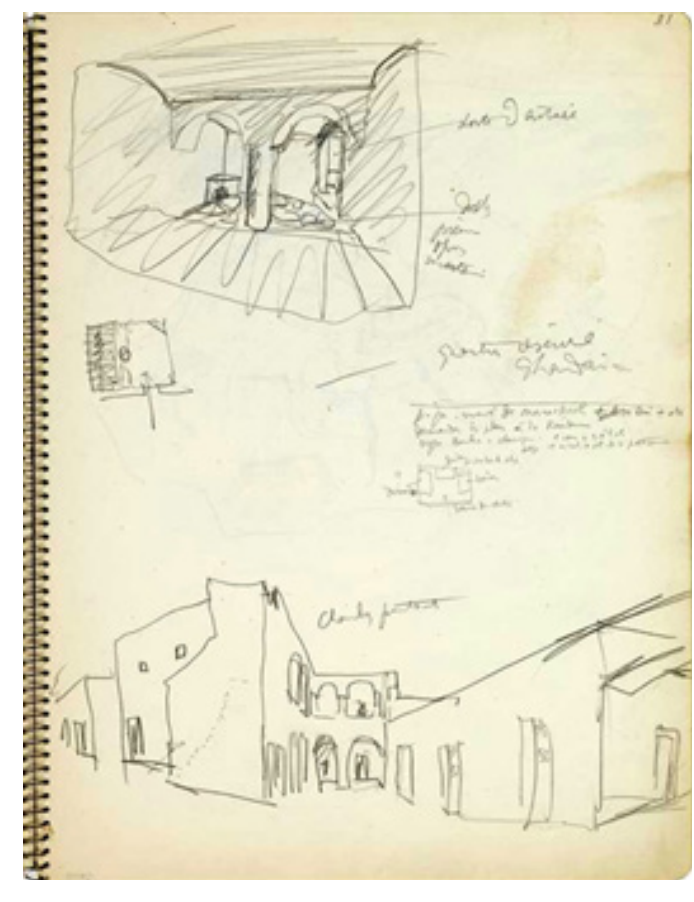

Figura 11: Le Corbusier, dibujos de las calles de Ghardaïa y el interior de una de las viviendas, 1931

Fuente: Fondation Le Corbusier (2014)

El impacto de estas arquitecturas fue tan positivo en Le Corbusier que llegó a pensar acerca de la conveniencia del conocimiento de aquellas lecciones que se desprendían de la arquitectura vernácula por parte de los estudiantes de arquitectura. En 1941 escribió: 
Deberíamos traer aquí, durante una primavera y un verano, a los alumnos de una gran escuela [...] Esos inminentes arquitectos descubrirían, entusiasmados, la verdadera arquitectura que se adueñaría de sus corazones y sus mentes. Año tras año, equipo tras equipo estudiarían granjas, pueblos y ciudades, de norte a sur del país (Le Corbusier, 1972 (1941), p.140)

La actitud en Argel fue similar a la que había tenido en las aldeas de M'Zab. Para Le Corbusier las casas se cerraban sobre sus muros sin huecos al exterior. La vida interior florecía en el "frescor, la quietud, el encanto de las proporciones y el sabor de una arquitectura humana". (1935).

Estos estudios previos fueron determinantes para el Plan Obús de 1931, como así aparece recogido en La Ville Radieuse, lo que le otorga la importancia que realmente tuvo en el momento de afrontar el proyecto 7 . Por ejemplo, utilizó el estudio de la Casbah desde una doble perspectiva urbana y arquitectónica. A nivel urbano destacó su relación con la escala humana, la inserción en el paisaje, su unidad arquitectónica, aspectos que él consideraba pertenecientes a la estructura original de la ciudad árabe. La unidad formal estaba basada en el diseño modular de una "geometría elemental" de elementos cúbicos. Se trata de una descripción similar a la que, como ya hemos hecho referencia, ofreció durante el viaje de Oriente sobre Estambul, considerada por Le Corbusier como una obra maestra del urbanismo (Le Corbusier, 1941).

Le Corbusier prestó especial atención al diseño de la vivienda proponiendo un sistema de agregación de espacios construidos alrededor de un vacío central con vistas a la sala de estar que evocaban sus casas de los años veinte y las casas árabes en torno al patio que había visto en la región. Consideraba aquellos espacios como "células", un concepto clave a la hora de analizar la Casbah y las aldeas de M'Zab: "la clef=la cellule=des hommes=du bonheur." (Le Corbusier, 1935). En La Ville Radieuse reconoció que para el proyecto sobre el suelo inaccesible de Fort-L'Empereur reintegraba los: "principios fundamentales de la casa morisca: el contraste de alturas diversas, el patio abierto sobre el jardín cerrado por altos muros, las vistas al mar" (1935). Describía su propuesta como de "buen regionalismo".

Se pueden establecer otros vínculos entre la arquitectura vernácula norteafricana con arquitecturas posteriores. Es el caso de Chapelle Notre Dame du Haut (1955), en Ronchamp, que, siendo posterior al periodo estudiado, no podemos dejar pasar desapercibidas las relaciones que autores como Gresleri (1987) han establecido: compara los huecos en los muros que sirven de alacena de la vivienda árabe con las hornacinas de la Iglesia, las pequeñas ventanas de las casas de M'Zab con los huecos por los que la luz entra al interior de la iglesia, el ambiente sombrío y fresco de las casas de Argelia con la atmósfera en penumbra que invita a la meditación, la rugosidad del enlucido pintado de blanco, entre otros.

Junto a estos grandes proyectos para Argel encontramos otros de pequeña entidad, aunque muy significativos,

\footnotetext{
${ }^{7}$ Los proyectos para Argel comenzaron en 1931 y terminaron en 1942. Le Corbusier publicó los materiales de La Ville Radieuse en Plans (Themes préparatoires á l'action. Organe mensuel du comité central d'action régionaliste, 1933-1936).
}

como es el caso de la Villa de Madame H. de Mandrot en Le Pradet, Francia. Le Corbusier (1934) prestó especial atención en los tipos vernáculos de la Provenza francesa, como por ejemplo en la utilización de materiales tradicionales. El proyecto resultante se adaptaba al paisaje rural de la Provenza, pero sin incurrir en la reproducción mimética de los detalles y la arquitectura local, que le hubiera acercado a posiciones regionalistas tan criticadas por el mismo en Vers une architecture (Martínez de Guereñu, 2005, p. 76).

La configuración estructural y material con muros de carga de piedra local, pone de manifiesto el interés por relacionar arquitectura y entorno en lo que se refiere al diálogo que se puede establecer entre ellos. Este hecho implicaba una relación de la obra con el suelo distinta a las que podía haber utilizado en proyectos anteriores, como por ejemplo los pilotes de la Villa Savoye (Figura 12).

Los volúmenes se configuran en torno a la terraza, un elemento que aparece en sus cuatro villas autónomas construidas durante la década anterior y que, en este caso, encarna una serie de cualidades poéticas que Le Corbusier (1933) se encargó de explicar en "Quel rôle Joue L'Esprit Poétique...?".

En cuanto al diálogo que estableció con el paisaje local y la arquitectura vernácula de la región convierten a la Villa Mandrot -cabría citar también la Maison Errazuriz en Chile- en una obra que hace de charnela entre las obras de la década anterior y en ejemplo capital para tratar de dilucidar su postura frente a lo vernáculo y el mundo de la máquina en esta nueva década de 1930.

\section{Discusión de resultados}

La posibilidad que nos ofrece una visión conjunta de los cuatro periodos nos permite realizar lecturas cruzadas teniendo en cuenta los hallazgos más relevantes en relación con lo vernáculo. En el primer periodo, comprendido entre 1904 y 1908 , observamos una especial sensibilidad e interés por la naturaleza y el paisaje local, la cultura regionalista y la arquitectura vernácula del Jura. La villa Fallet, una de sus primeras obras, encarna esta sensibilidad en una síntesis de aspectos vernáculos propios del Jura y de una cultura regionalista. En el segundo periodo estudiado, comprendido entre 1908 y 1918, destaca el papel desempeñado por lo vernáculo que le era ajeno, perteneciente a otras culturas y lugares, y para cuyo conocimiento cobró especial relevancia la experiencia iniciática del viaje. En su obra construida, como por ejemplo la villa Jeanneret-Perret, podemos identificar aspectos relativos a arquitecturas vernáculas de otras regiones, como consecuencia de experiencias que el propio autor reconoce en sus escritos. En la tercera época sobresale la aparente contradicción entre lo vernáculo y el purismo de una modernidad ortodoxa del periodo de entreguerras que Passanti (1997) ha abordado específicamente. En este periodo se observa la reaparición de los conocimientos previos adquiridos, encubiertos bajo un modelo conceptual basado en la relación natural entre la sociedad y sus artefactos, en la línea de Muthesius o Schultze-Naumburg, en una suerte 

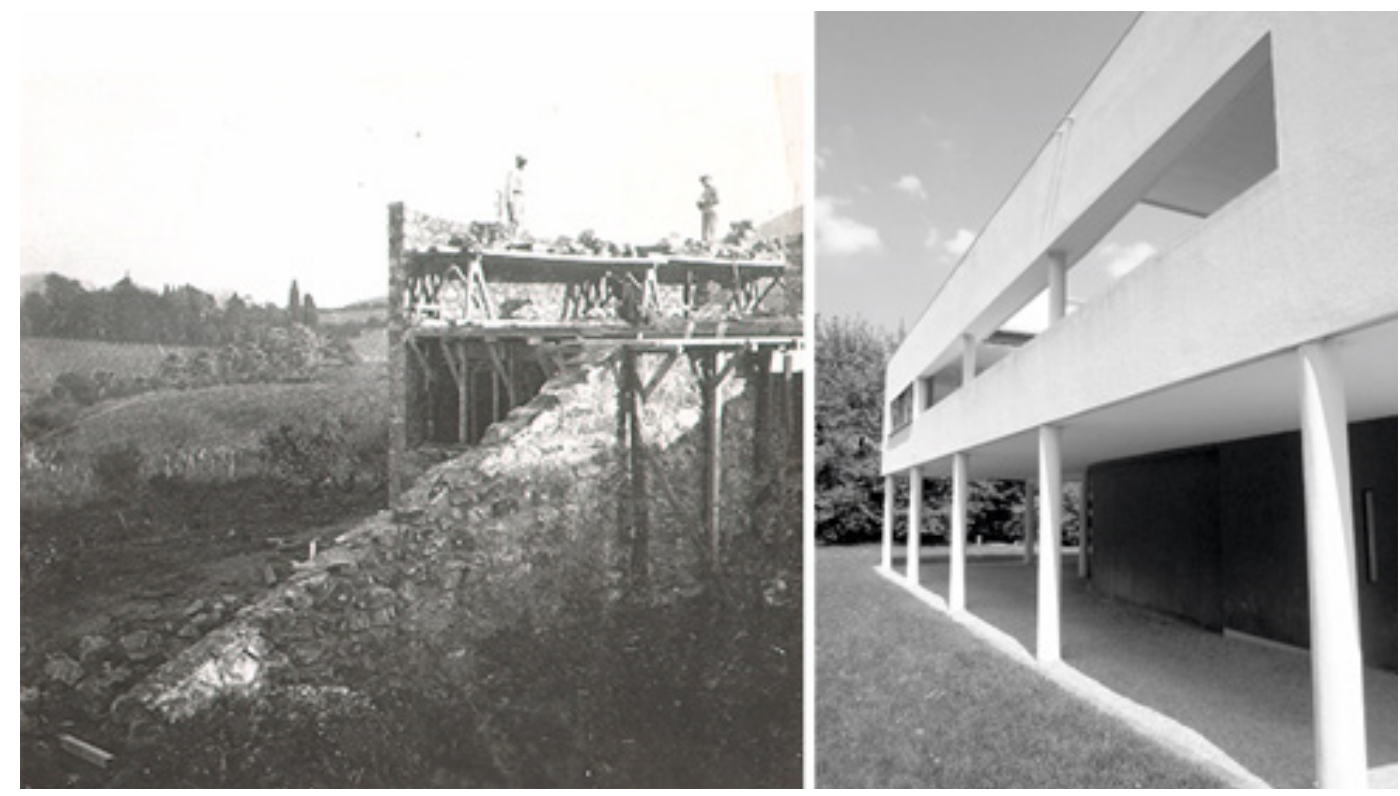

Figura 12: A la izquierda, construcción de la Villa Mandrot, Le Pradet, Francia, 1930; a la derecha, alzado suroeste de la Villa Savoye, Poissy, Francia, 1929

Fuente: Fondation Le Corbusier (L2-19-24-001) e imagen del autor (2014) respectivamente

de modernidad vernácula. A nivel formal, se pueden reconocer rasgos y aspectos de arquitecturas vernáculas estudiadas previamente por Le Corbusier en su arquitectura purista, como es el caso de La Villa Savoye, que algunos autores han estudiado ampliamente, si bien las referencias directas las encontramos, principalmente, en su obra escrita, como es el caso de Précisions. En el cuarto periodo, brutalista, la cuestión nuclear radicó en ahondar en el fondo del lenguaje arquitectónico, descartar las apariencias para detectar, más allá de lo evidente, significados más profundos de lo vernáculo. Proyectos como la Villa Mandrot o sus proyectos para Argel ponen de manifiesto la búsqueda de Le Corbusier de fuentes y motivos vernáculos en las regiones donde llevó a cabo estos proyectos con un giro, evidente, en su materialización según las condiciones particulares.

\section{Consideraciones finales}

A lo largo del texto se han recopilado evidencias sobre cuestiones tipológicas, decorativas, espaciales, técnicas o urbanas que conciernen a lo vernáculo en la trayectoria de Le Corbusier durante el periodo comprendido entre 1904 y 1939. Comprobamos cómo estos aspectos contribuyeron a la definición de un lenguaje arquitectónico propio según una relación de causalidad, como se desprende de sus dibujos y textos en cuadernos de viajes, cartas o escritos. Las influencias, experiencias 0 enseñanzas recibidas en un periodo reaparecen en los siguientes y se manifiestan de diferente modo. En relación con esta temática corbusieriana hemos podido identificar cuatro periodos presididos por lo vernáculo en su expresión más amplia- y en los que, sin embargo, apreciamos matices que los diferencian.

Teniendo en cuenta lo anterior, podemos considerar la componente vernácula como un hilo conductor desde sus primeros años de formación y primeras obras, la década "purista" de los años veinte y, asimismo, en una estética más brutalista a partir de los años treinta. Esta lectura no exime el papel desempeñado por otras influencias como la geométrica, la clásica, la de la máquina y la funcional, ampliamente estudiadas por investigadores. La obra y pensamiento de Le Corbusier se muestra enciclopédica en sus ámbitos temáticos y poliédrica en sus interpretaciones, pues se debate en una incesante dialéctica entre polaridades en controversia: su deseo de armonía y proporción conviven con el discurso de la máquina, su anhelada mediterraneidad con la tradición centroeuropea, su amor por el pasado clásico y vernáculo con una vehemente pasión por el futuro. A este respecto se refirió el propio arquitecto en la conferencia impartida en "Amigos de las Artes" el 3 de octubre de 1929 bajo el título Liberarse de todo espíritu académico: "Me tildan de revolucionario. Voy a confesaros que no he tenido nunca más que un maestro: el pasado". En su discurso hacía alusión a "los museos, los viajes, los folklores" y afirmaba que había ido allá donde había formas puras "las del campesino o las del genio" (Le Corbusier, 1999, p. 49).

\section{Agradecimientos}

A la Fondation Le Corbusier. A la Universidad Politécnica de Cartagena por conceder la beca en el marco del Programa Erasmus de formación del PDI para realizar la estancia en París. 
Cómo citar este artículo/How to cite this article: Jimenez-Vicario, P., Ródenas-López, M. y Mestre-Martí M. (2021). De las granjas del Jura al valle de M'Zab. Influencias de lo vernáculo en Le Corbusier. Estoa. Revista de la Facultad de Arquitectura y Urbanismo de la Universidad de Cuenca, 10(20), 77-89. Doi: 10.18537/est.v010.n020.a07

\section{Referencias bibliográficas}

Baker, G. H. (1996). Le Corbusier: The Creative Search John Wiley \& Sons Inc.

Benton, T. (1987). Le 'rêve virgilien' et la Villa Savoye. En Le Corbusier et la Mediterranée, catàleg de l'exposició a Marsella. Parenthèses.

Brooks, H. A. (1997). Le Corbusier's formative years. Charles-Edouard Jeanneret at La Chaux-de-Fonds. University of Chicago Press.

Calatrava, J. (2012). Referentes literarios en e pensamiento de Le Corbusier. En Le Corbusier, mise au point. General de Ediciones de Arquitectura.

Çelik, Z. (1992). Le Corbusier, Orientalism, Colonialism. Assemblage (17), 58-77.

Daza Caicedo, R. (2015). Tras el viaje de Oriente. CharlesÉdouard Jeanneret - Le Corbusier. Fundación Caja de Arquitectos (Arquia).

Dumont, M-J. (Ed.). (2006). Le Corbusier. Lettres à Charles L'Eplattenier. Éditions du Linteau. Fondation Le Corbusier.

Gresleri, G. (1987). Les lecons du voyage d'Orient. En Le Corbusier et la Mediterranée: catàleg de l'exposició a Marsella, Centre de la Vieille Charité, juny-set 1987 (pp. 37-50). Parenthèses

Gresleri, G. (2002). The Balkans. En E. v. Moos y A Rüegg (Eds.), Le Corbusier before Le Corbusier, applied arts, architecture, painting, photography, 1907-1922 exhibition. Yale University Press.

Jung, F. (1966). Le Corbusier et la 'Maison du Diable.' L'Impartial, (15).

Le Corbusier. (1923). Pedagogie. L’Esprit Nouveau, (19).

Le Corbusier y Jeanneret. P. (1929). Le Corbusier et Pierre Jeanneret: oeuvre complète 1910-1929. Birkhäuser Publishers.

Le Corbusier. (1931). Vers la 'Ville Radieuse'. Une nouvelle ville remplace une ancienne ville. Plans, (8).

Le Corbusier. (1933). Quel rôle Joue L’Esprit Poétique...? L'Architecture d'Aujourd'hui, (10), 63-64.

Le Corbusier y Jeanneret, P. (1934). Le Corbusier et Pierre Jeanneret: oeuvre complète 1929-1934. Birkhäuser Publishers.
Le Corbusier. (1935). La ville radieuse: éléments d'une doctrine d'urbanisme pour l'équipement de la civilisation machiniste. Vincent Fréal et Cie.

Le Corbusier. (1941). Le folklore est l'expression fleurie des traditions. Voici la France de ce mois, (16), 31-32.

Le Corbusier. (1957). Entretien avec les étudiants des écoles d'architecture. (Trabajo original publicado en 1943). Minuit.

Le Corbusier. (1972). Por las cuatro rutas. (Trabajo original publicado en 1941). Gustavo Gili.

Le Corbusier. (1978). Hacia una arquitectura. (1a ed. en 1923, Vers une architecture). Poseidon.

Le Corbusier. (1989). Une maison-un palais "a la recherche d'une unité architecturale". (1a ed. en 1928). Connivences.

Le Corbusier. (1993). El viaje de Oriente. (1a ed. en 1966). Colegio oficial de Aparejadores y Arquitectos técnicos de Murcia.

Le Corbusier. (1999). Precisiones respecto a un estado actual de la arquitectura y el urbanismo. (Trabajo original publicado en 1930). Ed. Apóstrofe.

Lejeune, J. F. y Sabatino, M. (Eds.). (2010). Modern architecture and the Mediterranean, vernacular dialogues and contested identities. Routledge.

Martínez de Guereñu, L. (2005). A Vernacular Mechanism for Poetic Reactions: The Villa Mandrot in Le Pradet. En Massilia: Anuario de Estudios Lecorbusierianos (pp 56-77). Associacio d'idees, Centre d'Investigacions Estétiques.

Passanti, F. (1997). The Vernacular, Modernism, and Le Corbusier. Journal of the Society of Architectural Historians, 56 (4), 438-451.

Passanti, F. (2002). Architecture: Proportion, Classicism and other Issues. En E. Moos y A. Rüegg (Eds.), Le Corbusier before Le Corbusier, applied arts, architecture, painting, photography, 1907-1922 exhibition, Yale University Press.

Pauly, D. (Ed). (1987). Le Corbusier et la Mediterranée, catàleg de l'exposició a Marsella, Parenthèses.

Schubert, L. (2002). Jeanneret, the City, and Photography. En E. Moos y A. Rüegg (Eds.), Le Corbusier before Le Corbusier, applied arts, architecture, painting, photography, 1907-1922 exhibition (pp. 55-68). Yale University Press.

Vogt, A. M. (1998). Le Corbusier the noble savage: Toward archaeology of modernism. The MIT Press.

Zaknic, I. (2017). Le Corbusier, history and tradition. En A. Rabaca et al. (Ed.), August Klipstein's Orient-Reise, companion to Le Corbusier's Journey to the East, 1911, Coimbra. 